\title{
INFLUÊNCIA DAS CONDIÇÕES DE AERAÇÃO NO TRATAMENTO DE EFLUENTES FENÓLICOS COM BIOFILMES EM REATOR AERÓBIO
}

\section{INFLUENCE OF AERATION CONDITIONS IN PHENOLICS EFFLUENTS TREATMENT USING BIOFILMS IN AEROBIC REACTOR}

\section{ALFREDO EDUARDO MAIORANO}

Engenheiro Químico. Doutor em Engenharia Química pela Escola Politécnica da Universidade de São Paulo.

Pesquisador do Instituto de Pesquisas Tecnológicas do Estado de São Paulo S.A

\section{MARISA ZUCCOLO-FIERI}

Engenheiro Químico. Doutora em Engenharia Química pela Universidade de Chile. Pesquisadora do Instituto de Pesquisas Tecnológicas do Estado de São Paulo S.A

\section{José MARCIO CARTER}

Bacharel em Química. Mestre em Biotecnologia. Pesquisador do Instituto de Pesquisas Tecnológicas do Estado de São Paulo S.A

\section{Alberto José Moitta da Costa}

Engenheiro Químico. Doutor em Engenharia Hidráulica e Saneamento pela Escola Politécnica da Universidade de São Paulo. Pesquisador do Instituto de Pesquisas Tecnológicas do Estado de São Paulo S.A

\section{JADER VIEIRA LEITE}

Engenheiro Químico. Doutor em Engenharia Hidráulica e Saneamento pela Escola Politécnica da Universidade de São Paulo. Pesquisador do Instituto de Pesquisas Tecnológicas do Estado de São Paulo S.A

\section{CÁSSIA REGINA SANCHEZ}

Bióloga. Mestre em Microbiologia pelo Instituto de Ciências Biomédicas da Universidade de São Paulo. Pesquisador do Instituto de Pesquisas Tecnológicas do Estado de São Paulo S.A

LUIZ ROBERTO MAGOSSI

Técnico do Instituto de Pesquisas Tecnológicas do Estado de São Paulo S.A

\section{RENATO DE JESUS ANDRADE}

Técnico do Instituto de Pesquisas Tecnológicas do Estado de São Paulo S.A

\section{MÁRCIO HENRIQUE TERRA}

Aluno do Instituto de Química da Universidade de São Paulo, Bolsista do Instituto de Pesquisas Tecnológicas do Estado de São Paulo S.A

\section{Recebido: 05/11/04 Aceito: 01/10/05}

\section{RESUMO}

No presente trabalho foi estudada a influência das condiçōes de aeração no tratamento de efluentes fenólicos com biofilmes. Os ensaios foram realizados com efluente sintético para simular dejetos industriais com elevadas concentraçōes de fenol. Foram testadas vazôes de aeração de $0,7,1,6,2,3$ vvm na cinética de biodegradação de fenol. Nas melhores condições testadas, quais sejam: reator de leito empacotado, com suporte de esferas de cerâmica e vazão de $2,3 \mathrm{vvm}$, foi atingida eficiência de remoção de fenol de aproximadamente $96 \%$.

PALAVRAS-CHAVE: Efluentes fenólicos, fenol, biofilme, reator de leito empacotado, biodegradação.

\section{ABSTRACTS}

A process for phenol biodegradation using biofilms was studied, using a synthetic waste to simulate industrial wastewater with high phenol concentrations. The aim of the experiments was to verify the influence of the aeration of 0.7, 1.6, $2.3 \mathrm{vvm}$ in the kinetics of phenol biodegradation. In the best experimented conditions used that were: packed bead reactor, ceramic spheres support and flow rate of $2.3 \mathrm{vvm}$, was achieved phenol removal efficiency near $96 \%$.

KEYWORDS: Phenolic effluents, phenol, biofilm, packed bead reactor, biodegradation. 


\section{INTRODUÇÃO}

Os sistemas descritos na literatura para o tratamento de vários tipos de efluentes, inclusive aqueles contendo fenol, indicam que o processo biológico convencional com lodo ativado vem sendo o mais usado. As células do lodo ativado, como todos microrganismos apresentam a característica de aderirem firmemente a praticamente qualquer superfície em ambiente aquoso. As células assim imobilizadas crescem, reproduzem-se e geram polissacarídeos que, freqüentemente, formam uma matriz de fibras sobre a qual novas células se aderem, formando uma estrutura porosa chamada biofilme (Characklis \& Marshall, 1990). Esta estrutura permite o fluxo de meio líquido através de canais e, conseqüentemente, as limitaçóes para difusão de oxigênio criam zonas propícias para o cultivo de microrganismos aeróbios e anaeróbios. O biofilme é, portanto, um ambiente heterogêneo, com presença de processos fermentativos aeróbios e anaeróbios, o que o distingue de outros sistemas microbiológicos.

Pode-se distinguir pelo menos 5 ambientes diferentes no sistema de biofilme: substrato, base e superfície do biofilme, meio líquido e fase gasosa. A interação entre eles ocorre por processos de transferência interfaciais ou transporte. Biorreatores com microrganismos imobilizados apresentam altas taxas de conversão e processos mais estáveis (Hamed et al, 2003). As maiores aplicações de biofilmes estão na remoção de partículas e contaminantes dissolvidos em águas naturais em estações de tratamento de água e esgoto, por intermédio de vários tipos de processos como filtros biológicos, bio-discos e reatores de leito fluidizado.

Entre os suportes utilizados para formação de biofilme podem ser citados areia, carvão ativado, poliuretano, esfera cerâmica (Briski et al, 1990; Koch et al, 1991; Silva, 1995; Wu et al, 1999).

Silva (1995) estudou em escala piloto o tratamento aeróbio de fenol em reator biológico de leito fluidizado, utilizando areia como suporte para o biofilme de Pseudomonas putida. Concentrações de fenol no efluente entre 51 e $1588 \mathrm{mg} / \mathrm{L}$, com tempos de retenção entre 0,54 a 7,01h e velocidade superficial do ar de 0,9 a $1,8 \mathrm{~cm} / \mathrm{s}$, resultaram em eficiências de remoção de fenol entre $87,2 \%$ e $98,9 \%$.

Hamoda et al (1987) estudaram a remoção de fenol utilizando biofilmes submersos e aerados. As concentrações de fenol testadas variaram entre 190 e $900 \mathrm{mg} / \mathrm{L}$, a taxa de aplicação entre 0,02 e $0,22 \mathrm{~m}^{3} / \mathrm{m}^{2}$ dia. Foi obtida uma eficiência de fenol de 99,9\%, que variou inversamente com a concentração de fenol na entrada do reator.

O processo de lodos ativados com células imobilizadas sobre esferas de cerâmica foi estudado por Wu et al (1999). Efluentes contendo 353-1911 mg/L de DQO, 11,6-55,7 mg/L de óleo, $1,57-48,7 \mathrm{mg} / \mathrm{L}$ de fenol, 10,1-53,5 mg/L de $\mathrm{NH}_{4}^{+}$e 2,3-5,4 mg/L de $\mathrm{PO}_{4}^{3-}$ foram biodegradados com porcentagens de remoção entre 75 e $87 \%$.

No presente trabalho foi estudado o processo de tratamento de efluentes fenólicos com biofilme. Os ensaios realizados procuraram verificar a influência da aeração na remoção de fenol em reator aeróbio de leito empacotado com biofilme aderido em suporte de cerâmica.

\section{MATERIAIS E MÉTODOS}

\section{Microrganismos}

Os ensaios foram realizados com cultura mista proveniente de lodo de esgoto adaptado para tratamento de resíduos contendo fenol, cedido pelo Laboratório Lucas Nogueira Garcez do Departamento de Engenharia Hidráulica e Sanitária da EPUSP. Inicialmente um volume de lodo era sedimentado e o sobrenadante descartado. A seguir, o resíduo era lavado com água potável e então ressuspendido em volume de efluente sintético igual àquele descartado.

\section{Efluente}

O efluente sintético utilizado para os ensaios de biodegradação de fenol foi preparado com água de torneira, de maneira a simular um efluente industrial com a seguinte composição (g/L): fenol 0,500, $\mathrm{MgSO}_{4} .7 \mathrm{H}_{2} \mathrm{O} 0,330$; $\mathrm{MnSO}_{4} \quad 0,053 ; \mathrm{K}_{2} \mathrm{HPO}_{4} 0,053$; $\left(\mathrm{NH}_{4}\right)_{2} \mathrm{SO}_{4} 0,500 ; \mathrm{CaCl}_{2} 0,053$ (Costa, 1999).

\section{Condições dos ensaios}

Os ensaios foram realizados em uma coluna de vidro com diâmetro interno de $44 \mathrm{~mm}$, contendo tela de PVC na parte cônica inferior para suporte das esferas de cerâmica, com diâmetro de 2,5 a 3,0 mm, colocadas no biorreator até atingir a altura de $50 \mathrm{~mm}$. Foram transferidos $190 \mathrm{~mL}$ de efluente sintético, contendo $500 \mathrm{mg} / \mathrm{L}$ de fenol e iniciada a aeração. Uma alíquota da suspensão de microrganismos igual a $10 \%$ do volume de meio foi utilizada como inóculo e o biorreator foi incubado em estufa a $30^{\circ} \mathrm{C}$. Nas primeiras $24 \mathrm{~h}$, o ensaio foi conduzido na forma de batelada para a formação do biofilme. Após esse período, foi iniciada a fase contínua, com a alimentação do biorreator com efluente sintético contendo $500 \mathrm{mg} / \mathrm{L}$ de fenol, através de uma bomba peristáltica, pela parte inferior do biorreator. Esta condição foi mantida para todos os ensaios e corresponde a carga orgânica volumétrica de $11,7 \mathrm{~kg} / \mathrm{m}^{3}$.d e tempo de retenção hidráulica igual a $2,3 \mathrm{~h}$. O efluente foi continuamente retirado pela parte superior do biorreator, utilizando-se uma bomba peristáltica. A variável estudada nesses ensaios foi a vazão de aeração, cujos valores foram de: $0,7,1,6$ e $2,3 \mathrm{vol} / \mathrm{vol} \mathrm{min}$ (vvm).

\section{Metodologia analítica}

Em todos os ensaios as amostras coletadas, na saída do biorreator, ao longo do processo foram inicialmente filtradas em membrana Millipore 0,22 $\mu \mathrm{m}$. O resíduo sólido foi destinado a determinação da concentração celular e o filtrado foi utilizado para determinaçôes de concentrações de fenol e DQO. A concentração celular foi determinada por método gravimétrico através da secagem até peso constante. A concentração de fenol foi determinada conforme metodologia descrita por Leite (1997). A DQO foi determinada através do método colorimétrico conforme descrito em APHA/WEF/ASCE (1998). A eficiência de remoção de fenol $(E R)$ foi calculada conforme equação (1).

$\mathrm{ER}=\frac{[\mathrm{fenol}]_{\mathrm{i}}-[\mathrm{fenol}]_{\mathrm{t}}}{[\text { fenol }]_{\mathrm{i}}} * 100$

onde: $[\text { fenol }]_{\mathrm{i}}=$ concentração inicial de fenol $(\mathrm{mg} / \mathrm{L}) ;[\text { fenol }]_{\mathrm{t}}=$ concentração de fenol no efluente $(\mathrm{mg} / \mathrm{L})$.

\section{RESULTADOS E DISCUSSÃO}

Considerando que o objetivo deste trabalho foi verificar a influência da aeração na remoção de fenol, verificou-se a possibilidade de arraste deste poluente pelo ar. Foram testadas vazões de aeração de 1,5 a 2,4 vvm, não sendo observado 
arraste significativo de fenol (resultados não mostrados).

Sendo a DQO um parâmetro importante relacionado à quantidade de matéria orgânica presente nos efluentes industriais, foi verificada a existência de correlação entre DQO e concentração de fenol. Assim, foram preparadas soluçóes do efluente sintético, com concentrações variadas de fenol, nas quais determinouse a DQO. Os resultados mostrados na Figura 1 indicam uma boa proporcionalidade entre as concentraçôes desses parâmetros. Diferenças nos valores dessa relação, obtidas com o efluente do biorreator, indicam a presença de outros compostos, diferentes de fenol, resultantes da biodegradação não completa desse poluente (González et al, 2001).

Os resultados obtidos no ensaio 1 , realizado com vazão de ar de 0,7 vvm, são mostrados na Figura 2a. Conforme pode-se observar, a concentração celular (X) medida na saída do biorreator manteve-se bastante baixa até cerca de $100 \mathrm{~h}$ de processo, indicando uma boa retenção da biomassa. A partir desse tempo há uma tendência de aumento da concentração de biomassa na saída do biorreator, provavelmente devido ao desprendimento das células do suporte. Não foi observada a correlação entre a concentração de fenol e a DQO apontada na Figura 1, apesar dessas curvas apresentarem um perfil bastante semelhante. A concentração de fenol no efluente do biorreator apresentou variaçōes, não sendo possível alcançar o estado estacionário, resultando em baixos valores de eficiência de remoção de fenol. Essa instabilidade possivelmente pode ser conseqüência da carga orgânica alimentada em relação ao crescimento celular obtido. A concentração celular na saída do biorreator no início da fase contínua foi resultante do arraste de células não aderidas ao suporte cerâmico e foi muito baixo, cerca de $0,04 \mathrm{~g} / \mathrm{L}$. Assim, pode-se supor que a vazão de ar tenha limitado o crescimento celular na fase em batelada. Além disso, no final da fase em batelada verificou-se que cerca de $94 \%$ da quantidade inicial de fenol foi degradada, mas não foi mineralizada, visto a alta DQO obtida, de cerca de $537 \mathrm{mgO}_{2} / \mathrm{L}$, indicando também que a baixa vazão de aeração limita a mineralização deste poluente. Após $168 \mathrm{~h}$ de ensaio em regime contínuo, observou-se pronunciado aumento da concentração de células e de fenol no efluente, indicando o início do processo de lavagem do biorreator.

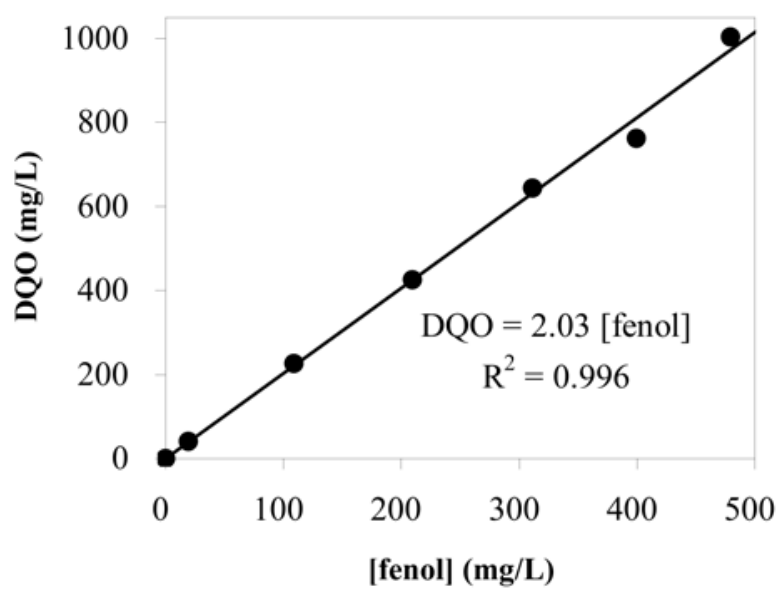

\section{Figura I - Correlação entre concentração de fenol [fenol] e DQO}

No ensaio 2, realizado com alimentação de ar de 1,6 vvm, a concentração celular no efluente do biorreator mostrou um comportamento inverso ao observado no ensaio anterior, apresentando uma diminuição ao longo do tempo, conforme pode-se observar na Figura $2 \mathrm{~b}$. No início da fase de alimentação contínua, nota-se que a concentração celular na saída do biorreator foi cerca de 11 vezes maior do que no primeiro ensaio. Como a vazão de ar nesse ensaio foi cerca de 2,3 vezes maior que no ensaio anterior, provavelmente resultou em crescimento celular mais intenso na fase em batelada. Por outro lado, provocou maior agitação, acarretando maior arraste da biomassa para o efluente do biorreator, principalmente no término da fase em batelada e início da fase contínua. Observou-se ainda que a cinética de biodegradação de fenol apresentou menor oscilação e variação, tendendo para a fase estacionária a partir de $118 \mathrm{~h}$ de ensaio. A eficiência de remoção de fenol atingiu um valor médio de cerca de $89 \%$, bem mais alto que a observada no ensaio anterior, com velocidade de degradação de fenol calculada em $5,8 \mathrm{~g}$ fenol/L dia.

O ensaio 3 foi realizado com vazão de aeração de 2,3 vvm, sendo esta 3,3 e 1,4 vezes maior do que aquelas usadas nos ensaios 1 e 2 , respectivamente. $\mathrm{O}$ perfil da curva da concentração celular na saída do biorreator, Figura 2c, foi semelhante ao do ensaio 2, pelos motivos já apontados, porém com velocidade de arraste de biomassa muito maior. Com apenas $23 \mathrm{~h}$ de ensaio atingiu-se o mais baixo valor de biomassa na saída do biorreator e a partir desse instante notou-se uma tendência de aumento desse parâmetro. Não foi possível notar visualmente diferenças neste ensaio com os demais em relação à biomassa aderida ao suporte que, apesar disso, apresentou forte atividade de biodegradação de fenol, resultando em rápida remoção deste poluente. Observou-se que a partir de $47 \mathrm{~h}$ de ensaio foi atingido o estado estacionário, resultando em uma concentração final de fenol na saída do biorreator de $21 \mathrm{mg} / \mathrm{L}$ com eficiência de remoção de fenol de 95,6\% e com velocidade de degradação de $6,1 \mathrm{~g}$ fenol/L dia.

Os valores obtidos de velocidade de degradação de fenol estão próximos dos reportados na literatura. Prieto et al (2002) reportaram valores de $7,2 \mathrm{~g} \mathrm{fenol} / \mathrm{L}$ dia, porém alimentando um biorreator de leito empacotado com uma carga orgânica 4 vezes menor do que aquela usada neste trabalho.

O ensaio 4 teve por objetivo verificar a influência da concentração de inóculo na cinética de biodegradação de fenol. Assim, este foi realizado com vazão de aeração de 2,3 vvm, a melhor condição de aeração obtida nos ensaios anteriores e com inóculo 10 vezes mais concentrado. Os resultados obtidos são mostrados na Figura 3. O estado estacionário neste último ensaio foi atingido após $76 \mathrm{~h}$ de fermentação, enquanto que no ensaio 3 teve início a partir de $47 \mathrm{~h}$ de biodegradação. Os perfis das curvas de DQO, concentração de fenol e concentração de biomassa, no estado estacionário, apresentaram perfis bastante semelhantes para os dois ensaios. Neste ensaio, obteve-se uma concentração de fenol residual média de $24,5 \mathrm{mg} / \mathrm{L}$ e eficiência de remoção de fenol de cerca de $95 \%$. A comparação dos resultados obtidos nes- 
ses dois ensaios permite afirmar que o aumento da concentração do inóculo não resultou em melhoria do processo de biodegradação de fenol. Esse resultado, provavelmente foi conseqüência do fato de que como a superfície para crescimento do biofilme foi praticamente constante nos ensaios, a quantidade de biofilme formada na etapa de operação em batelada foi a mesma para as concentraçóes de inóculo testadas.

A Figura 4 mostra as concentrações de fenol, de DQO e eficiência de remoção de fenol no efluente do biorreator em função da vazão de aeração.

Pode-se observar que a concentração de fenol neste efluente diminuiu com o aumento da vazão de aeração até cerca de 1,6 vvm, após a qual um grande aumento da vazão de aeração não resultou em diferença significativa da concentração deste poluente. Por outro lado, a remoção de fenol foi proporcional ao aumento da vazão de aeração atingindo valores maiores que $95 \%$ para vazóes em torno de 2,3 vvm. O perfil de redução de DQO apresenta comportamento similar ao observado para a concentração de fenol, com acentuada redução até cerca de 1,6 vvm, passando a ser menos significativa com o aumento da vazão de aeração. Observou-se ainda que a redução da DQO foi cerca de 2,7 vezes menor que a esperada, conforme a relação apresentada na Figura 1, indicando que não foi possível obter a total mineralização do poluente nas condiçôes testadas.

\section{CONCLUSÕES}

Os resultados obtidos confirmaram o uso potencial de biorreatores aeróbios com biofilmes, formados por culturas adaptadas à biodegradação de fenol, para a remoção de elevadas concentraçóes deste poluente.

A vazão de aeração mostrou efeito significativo tanto na velocidade de degradação como na eficiência de remoção de fenol. A melhor condição de operação do biorreator foi obtida utilizando-se vazão de aeração de $2,3 \mathrm{vvm}$, alcançandose remoção de fenol de 95,6 \% com velocidade de degradação de 6,1 g fenol/L.h.

\section{AGRADECIMENTOS}

Auxílio Financeiro: Instituto de Pesquisas Tecnológicas do Estado de São Paulo.
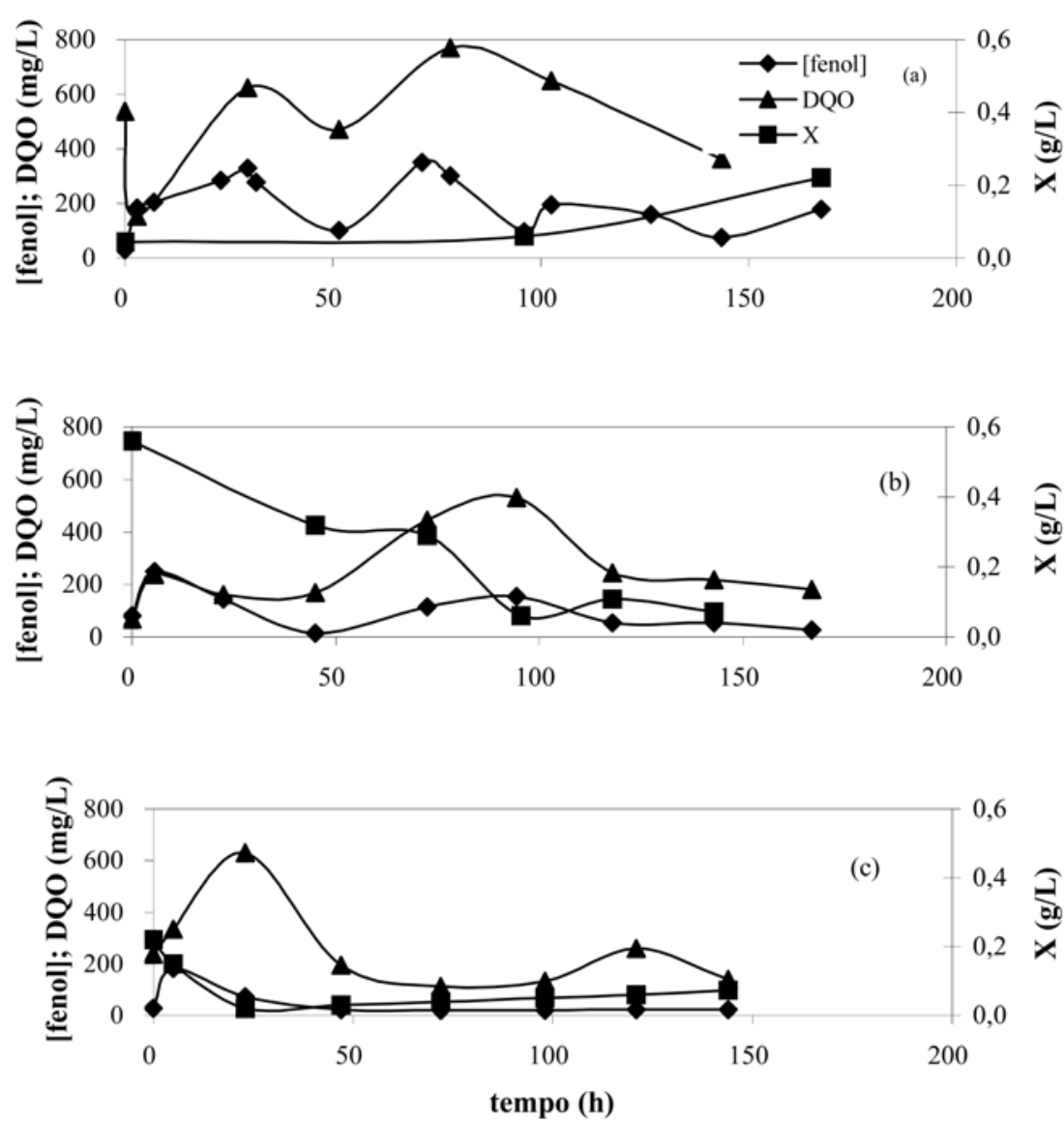

Figura 2 - Variação da concentração de fenol [fenol], DQO e biomassa (X) em função do tempo para as vazões de ar testadas: (a) 0,7 vw, (b) I,6 vvm, (c) 2,3 vvm

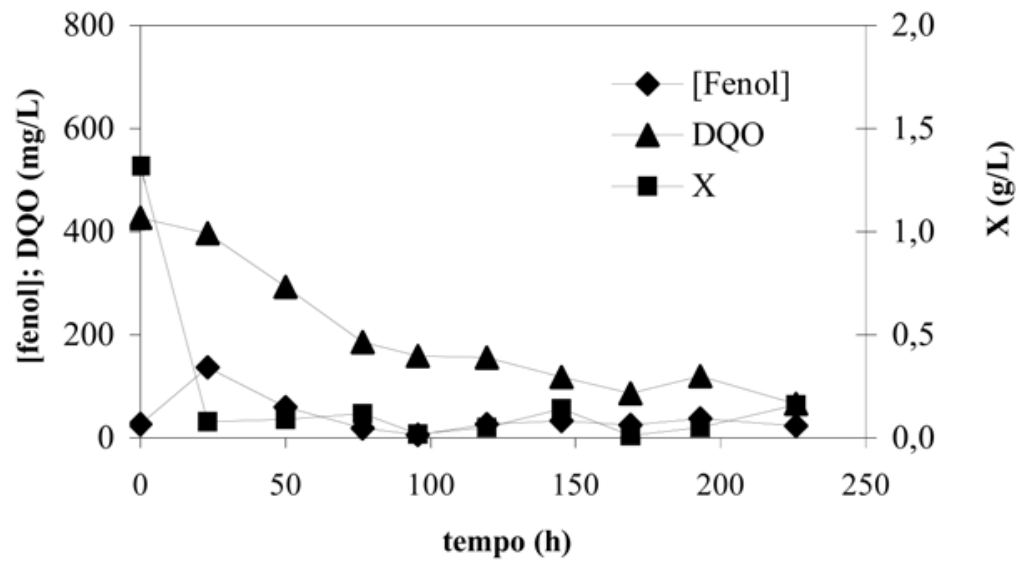

Figura 3 - Variação da concentração de fenol [fenol] e da DQO em função do tempo para ensaio com inóculo concentrado 


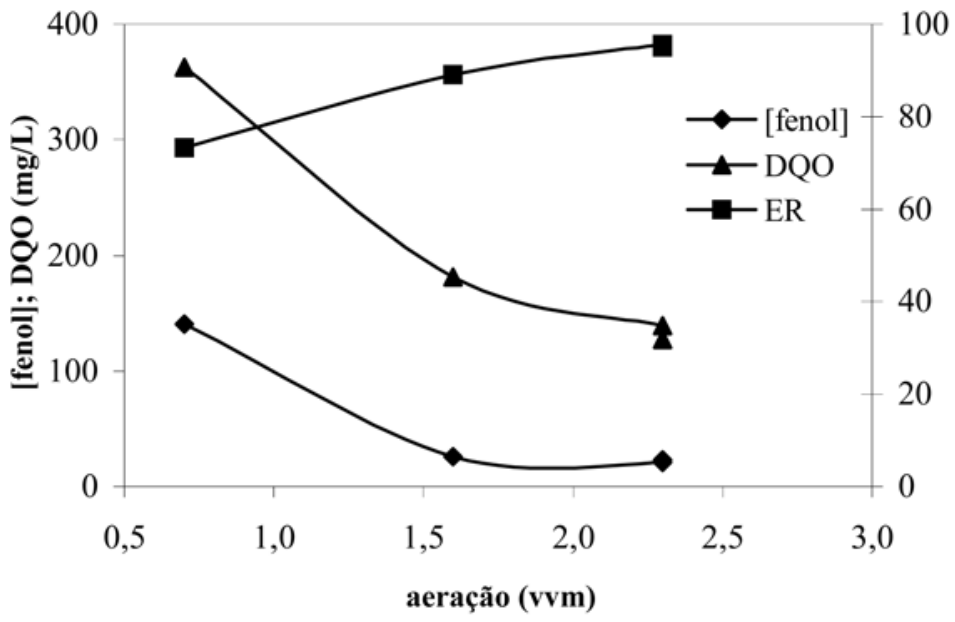

Figura 4 - Concentrações finais de fenol [fenol], de DQO e eficiência de remoção de fenol (ER) em função da aeração

\section{REFERÊNCIAS}

AMERICAN PUBLIC HEALT ASSOCIATION. Standard Methods for the Examination of Water and Wastewater, $20^{\text {th }}$ ed. APHA, Washington, DC, 1998.

BRISKI, F., JURIC, Z., MATANIC, H. Phenol biodegradation in waste water by mixed microbial population immobilized on different carriers. Prehrambeno-Tehnol. Biotehnol. Rev., v.28, n.1, p.17-21, 1990.

CHARACKLIS, W.G. \& MARSHALL, K.C. Biofilms. John Wiley \& Sons, INC. 1989.

COSTA, A.J.M.P. Estudo de tratabilidade de água residuária sintética simulando despejo liquido de coquerias. São Paulo. Tese (Doutora- do) Escola Politécnica, Universidade de São Paulo, 267 p. 1999.

GONZÁLEZ, G. et al. Biodegradation of phenolic industrial wastewater in a fluidezed bed bioreator with cells of Pseudomonas putida. Bioresource Technology, v. 80, p.137-142, 2001.

HAMED, T.A. et al. Substrate interactions during the biodegradation of benzene, toluene and phenol mixtures. Process Biochemistry, v.39, p.27-35, 2003.

HAMODA, M.F., AL-HADDAD, A.A., ABD-AL-BARY, M.F. Treatment of phenolic wastes in a aerated submerged fixed-film (ASFF) bioreactor. Journal of Biotechnology, v.5, n.4, p.279-292, 1987.
$\mathrm{KOCH}, \mathrm{B}$. et al. Sand and activated carbon as biofilm carriers for microbial degradation of phenols and nitrogen-containing aromatic compounds. Water Research, v.25, n.1, p.1-8, 1991.

LEITE, J.V. Avaliação da toxicidade do fenol em sistemas de lodos ativados - Utilização do método Fed-Batch Reactor (FTR) modificado. São Paulo. Dissertação (Mestrado) EP, Universidade de São Paulo. 185p. 1997.

PRIETO, M.B. et al. Degradation of phenol by Rhodococcus erythropolis UPV -1 immobilized on biolite in a packed-bed reator. Journal of Biotechnology, v.97, p.1-11, 2002.

SILVA, E.L. Tratamento aeróbio de fenol em reator de leito fluidizado trifásico. São Carlos. Tese (Doutorado). EESC, Universidade de São Paulo, 1995.

WU, X.L., ZHOU, P., QIAN, Y. Performance of an internal circulating three-phase fluidized bed bioreactor in treating petrochemical wastewater. Environmental Technology, v.20, n.3, p.269-275, 1999.

\section{Endereço para correspondência:}

Alfredo Eduardo Maiorano Instituto de Pesquisas Tecnológicas do Estado de São Paulo S.A. Divisão de Química Caixa Postal 014 I Agrupamento de Biotecnologia 0 I 064-970 São Paulo - SP - Brasil Tel.: (II) 3767-4829

Fax: (II) 3767-4052

E-mail:maiorano@ipt.br 